\section{BMJ Open Respiratory Research}

\title{
Association between self-reported moderate to vigorous physical activity and the rate of outpatient treated COPD exacerbations: retrospective cohort study
}

\author{
Huong Q Nguyen, ${ }^{1}$ Richard A Mularski, ${ }^{2}$ Marilyn L Moy, ${ }^{3,4}$ Janet S Lee, ${ }^{1}$ \\ Ernest Shen ${ }^{1}$
}

\begin{abstract}
To cite: Nguyen $\mathrm{HQ}$, Mularski RA, Moy ML, et al. Association between self-reported moderate to vigorous physical activity and the rate of outpatient treated COPD exacerbations: retrospective cohort study. BMJ Open Resp Res 2020;7:e000590. doi:10.1136/ bmjresp-2020-000590
\end{abstract}

Received 9 March 2020 Revised 24 April 2020 Accepted 29 April 2020
Check for updates

\section{(c) Author(s) (or their} employer(s)) 2020. Re-use permitted under CC BY-NC. No commercial re-use. See rights and permissions. Published by BMJ.

${ }^{1}$ Research and Evaluation, Kaiser Permanente Southern California Research and Evaluation, Pasadena, California, USA

${ }^{2}$ Center for Health Research, Kaiser Permanente Northwest, Portland, Oregon, USA

${ }^{3}$ Pulmonary Division, Harvard Medical School, Boston, Massachusetts, USA ${ }^{4}$ Pulmonary Division, VA Boston Health Care System West Roxbury Campus, West Roxbury, Massachusetts, USA

Correspondence to Dr Huong Q Nguyen; huong.q2.nguyen@kp.org

\section{ABSTRACT}

Introduction Little has been published regarding the relationship between physical activity $(\mathrm{PA})$ and outpatient treated, mild to moderate acute exacerbation of chronic obstructive pulmonary disease exacerbations (AECOPD). The purpose of this study was to determine the association between self-reported PA and outpatient treated AECOPD over 2 years using real-world data obtained from existing electronic medical records (EMRs).

Methods We included 44896 patients with a chronic obstructive pulmonary disease diagnosis from the EMR in this retrospective cohort study. Moderate to vigorous PA was measured via patient self-report, obtained during routine clinical care; patients were classified as inactive (0 min/week), insufficiently active (1-149 min/week) or active ( $\geq 150 \mathrm{~min} /$ week). AECOPDs were measured using both encounter and prescription fill (antibiotics and/or oral steroids) data. We used Poisson regression models to compare the unadjusted and adjusted rates of outpatient treated AECOPD over 2 years across the PA categories. Results In adjusted models, the 2-year AECOPD incidence rate ratio (IRR) was not different between the inactive and insufficiently inactive groups (IRR $0.98,95 \% \mathrm{Cl} 0.96$ to 1.01 ) and only marginally meaningful lower for the active group (IRR 0.97, 95\% Cl 0.95 to 0.98 ). Sensitivity analyses of patients meeting or not meeting obstructive criteria produced similar results with generally weak or nonsignificant associations.

Conclusion The lack of an association between PA and AECOPD contrasts with previous published findings of a strong relationship between moderate to vigorous $\mathrm{PA}$ and hospitalisations for severe AECOPD. This difference could partially be attributed to the imprecision of our measurements for both the exposure and outcome.

\section{BACKGROUND}

Observational studies consistently show that physical inactivity is associated with increased hospitalisations and mortality. ${ }^{1-5}$ We previously showed that hospitalised patients with chronic obstructive pulmonary disease (COPD) who were physically active in the

\section{Key message}

What is the association between self-reported physical activity (PA) and the rate of outpatient treated acute exacerbations of chronic obstructive pulmonary disease (AECOPD) ?

- The association between self-reported moderate to vigorous $\mathrm{PA}$ and the rate of mild to moderate outpatient treated AECOPD over 2 years of follow-up was generally weak or not significant.

- This is the largest cohort study using real-world data on patient self-reported PA and mild to moderate COPD exacerbations obtained from electronic medical records.

year prior to the index admission had a $34 \%$ lower risk of 30-day readmission ${ }^{6}$ and up to $47 \%$ lower risk of mortality in the 12 months following hospital discharge ${ }^{7}$ compared with inactive patients. Very little has been published regarding the relationship between physical activity (PA) and outpatient treated, mild to moderate acute exacerbations of chronic obstructive pulmonary disease (AECOPD) that do not result in hospitalisations. The purpose of this study was to determine the association between self-reported moderate to vigorous $\mathrm{PA}$, captured as part of routine care in a large integrated healthcare system, and the rate of outpatient treated AECOPD over 2 years.

\section{METHODS}

\section{Study design and setting}

We performed a retrospective cohort study using longitudinal electronic medical record (EMR) data from Kaiser Permanente Southern California (KPSC) and Kaiser Permanente Pacific Northwest (KPNW) healthcare systems. We identified all patients 
aged $>40$ years old with diagnosed COPD between January 2011 and September 2015 based on having $\geq 1$ encounter with an International Classification of Diseases, Ninth Revision, code for COPD (491 .XX, 492 .XX, 493.2X and 496) and $\geq 1$ dispensed inhaler. Baseline sociodemographic and clinical characteristics, Charlson Comorbidity Index, ${ }^{8}$ spirometry, lifestyle behaviours, inhaler use and healthcare use were obtained in the year prior to exacerbation ascertainment (October 2014-September 2015).

\section{SELF-REPORTED PA}

Every patient, regardless of their condition or presenting problem in the health system, is asked two questions that capture their regular PA during the intake process for all outpatient visits. ${ }^{9}$ This is called the exercise vital sign (EVS) and is presented as (1) 'On average, how many days per week do you engage in moderate to strenuous (vigorous) exercise (like a brisk walk)?' and (2) 'On average, how many minutes do you engage in exercise at this level?' These questions are typically asked by front office medical staff, and patients' responses are entered into the EMR. Response choices for days are categorical $(0-7)$. Minutes are recorded as $0,10,20,30,40,50,60$, 90, 120 and 150 min or greater. The EMR then multiplies the responses to display total minutes per week of moderate or vigorous PA. Patients can be categorised into three cohorts as used by the National Health and Examination Survey: inactive $(0 \mathrm{~min} /$ week $)$, insufficiently active (1-149 $\mathrm{min} /$ week) or active, meeting PA recommendations ( $\geq 150 \mathrm{~min} /$ week). We used all available EVS data in the year prior to ascertainment of COPD exacerbations to classify patients into their usual pattern of PA based on both the modal/median EVS values. The EVS has evidence of construct and predictive validity. ${ }^{6710}$

\section{COPD EXACERBATIONS}

Two years of follow-up data for outpatient treated AECOPD were obtained from October 2015 to September 2017 via pharmacy and use data. AECOPD have been identified by changes in the current therapy to include increased use of bronchodilators and a short course of prednisone and/or antibiotics. ${ }^{11}$ For this study, an outpatient AECOPD was defined as (1) encounters with a documented COPD diagnosis followed by a prescription fill of antibiotics, steroids, or antibiotics and steroids and (2) encounters with no documented COPD diagnosis but followed by a prescription fill of antibiotics and steroids, both within 2 days of the encounter; this definition yielded a sensitivity of $67 \%$ and a specificity of $84 \%$ based on a review of 185 charts. ${ }^{12}$

\section{STATISTICAL ANALYSES}

We used Poisson regression models to compare crude and adjusted rates of outpatient AECOPD per memberyear; the log of the latter was included as an offset term.
Covariates in adjusted models included age, gender, marital status, race/ethnicity, smoking status, use of inhaled steroids and oxygen, Charlson index, depression, anxiety, chronic pain, all-cause acute care use (hospitalisation, observation stay and $\mathrm{ED}$ visits) and number of outpatient treated AECOPD in the previous 12 months. Models were stratified by availability of spirometry and by Global initiative for chronic obstructive lung disease (GOLD) class. We also used negative binomial models to assess the sensitivity of our findings to possible overdispersion in AECOPD counts. Analyses were conducted using SAS V.9.4. A two-sided $p$ value of $<0.05$ was considered statistically significant.

\section{PATIENT AND PUBLIC INVOLVEMENT}

Since this study strictly relied on existing data via an approved waiver of written consent, we did not engage with patient stakeholders in the design or conduct of the analyses nor interpretation of the findings.

\section{RESULTS}

\section{Baseline characteristics}

Among 44896 eligible adults with COPD, 56\% were physically inactive; $23 \%$ were insufficiently active; and $21 \%$ were active. There were clinically and statistically meaningful differences in the gender distribution, smoking status, body mass index, GOLD class, oxygen use, comorbidities, and baseline all-cause and COPDspecific healthcare use across the PA categories (tables 1 and 2). Approximately a quarter of the patients did not have spirometry data $(25 \%)$ or had an forced expiratory volume in one second $\left(\mathrm{FEV}_{1}\right)$ :forced vital capacity (FVC) ratio of $\geq 0.70(26 \%)$. Patients who were inactive experienced more outpatient treated AECOPD at baseline compared with other patients.

\section{Association between PA and rate of outpatient treated COPD exacerbations over 2 years}

For the overall cohort, the unadjusted model showed a lower rate of AECOPD in the insufficiently active and active groups compared with the inactive group, but this was no longer significant in the adjusted model for the insufficiently inactive group (incidence rate ratio (adjusted IRR) $0.98,95 \%$ CI 0.96 to 1.01 ) and only marginally meaningful for the active group (adjusted IRR $0.97,95 \%$ CI 0.95 to 0.98 ) (table 3 ). There were no significant associations between PA and AECOPD for patients in GOLD classes I and II. For GOLD III/ IV patients, there appears to be some marginal though non-significant association between any PA and AECOPD (adjusted IRR 0.95, 95\% CI 0.90 to 1.00 ) compared with inactive patients. For patients with $\mathrm{FEV}_{1}: \mathrm{FVC}$ of $\geq 0.70$, the adjusted model showed that insufficiently active patients had lower AECOPD risk compared with inactive patients (IRR $0.90,95 \%$ CI 0.85 to 0.95 ). No significant associations were noted for patients who did not have 
Table 1 Baseline sociodemographic and clinical characteristics by self-reported moderate to vigorous physical activity (exercise vital sign)

\begin{tabular}{|c|c|c|c|c|}
\hline & Inactive ( $n=25$ 117) & $\begin{array}{l}\text { Insufficiently active } \\
(\mathrm{n}=10 \text { 221) }\end{array}$ & Active $(n=9558)$ & $P$ value \\
\hline Age (years) & $71.6(10.53)$ & $70.5(10.37)$ & $69.5(9.97)$ & $<0.01$ \\
\hline $40-49$ & $573(2 \%)$ & $293(3 \%)$ & $311(3 \%)$ & $<0.01$ \\
\hline $50-59$ & $2894(12 \%)$ & $1231(12 \%)$ & $1217(13 \%)$ & \\
\hline $60-69$ & $6647(26 \%)$ & $3038(30 \%)$ & 3026 (32\%) & \\
\hline $70-79$ & $8923(36 \%)$ & 3590 (35\%) & 3491 (37\%) & \\
\hline $80+$ & $6080(24 \%)$ & $2069(20 \%)$ & $1513(16 \%)$ & \\
\hline Female & $14129(56 \%)$ & 5545 (54\%) & $4307(45 \%)$ & $<0.01$ \\
\hline Marital status: partnered & 12988 (52\%) & 5502 (54\%) & $5486(57 \%)$ & $<0.01$ \\
\hline Education: college+ & $6238(25 \%)$ & $2795(28 \%)$ & 2910 (31\%) & $<0.01$ \\
\hline Median household income: $\geq \$ 50000$ & $14156(57 \%)$ & $5884(58 \%)$ & $5684(60 \%)$ & $<0.01$ \\
\hline Race/ethnicity: white & $19637(78 \%)$ & $7374(72 \%)$ & $7273(76 \%)$ & $<0.01$ \\
\hline Insurance status: public & $18142(72 \%)$ & $6959(68 \%)$ & $6543(68 \%)$ & $<0.01$ \\
\hline Smoking status & & & & $<0.01$ \\
\hline Never & $4248(17 \%)$ & $2126(21 \%)$ & $2027(21 \%)$ & \\
\hline Former & 15615 (62\%) & $6326(62 \%)$ & $6016(63 \%)$ & \\
\hline Current & $5037(20 \%)$ & $1687(17 \%)$ & $1431(15 \%)$ & \\
\hline Missing & $217(1 \%)$ & $82(1 \%)$ & $84(1 \%)$ & \\
\hline Body mass index & $30.2(27.81)$ & $28.9(6.97)$ & $27.7(6.77)$ & $<0.01$ \\
\hline Underweight $(<18.5)$ & $775(3 \%)$ & $240(2 \%)$ & $246(3 \%)$ & $<0.01$ \\
\hline Normal weight (18.5-24.9) & $5868(23 \%)$ & $2774(27 \%)$ & $3149(33 \%)$ & \\
\hline Overweight (25.0-29.9) & 7407 (29\%) & 3446 (34\%) & 3315 (35\%) & \\
\hline Obese $(>30)$ & 10860 (43\%) & 3693 (36\%) & $2779(29 \%)$ & \\
\hline Missing & $207(1 \%)$ & $68(1 \%)$ & $69(1 \%)$ & \\
\hline Spirometry & 18479 (74\%) & 7768 (76\%) & 7261 (76\%) & \\
\hline $\mathrm{FEV}_{1} / \mathrm{FVC}<0.70$ & $11802(47 \%)$ & $5035(49 \%)$ & $4910(51 \%)$ & $<0.01$ \\
\hline $\mathrm{FEV}_{1} / \mathrm{FVC}$ & $63.8(13.39)$ & $63.5(13.29)$ & $63.2(12.63)$ & $<0.01$ \\
\hline $\mathrm{FEV}_{1} \%$ predicted & $72.6(21.68)$ & $74.4(22.16)$ & $77.3(33.83)$ & $<0.01$ \\
\hline GOLD I ( $\geq 80 \%)$ & $2795(11 \%)$ & $1322(13 \%)$ & $1616(17 \%)$ & $<0.01$ \\
\hline GOLD II $\left(50 \% \leq \mathrm{FEV}_{1}<80 \%\right)$ & $6401(26 \%)$ & $2695(26 \%)$ & $2517(26 \%)$ & \\
\hline GOLD III/IV (FEV $<$ <50\%) & $2605(10 \%)$ & $1018(10 \%)$ & $777(8 \%)$ & \\
\hline $\mathrm{FEV}_{1} / \mathrm{FVC} \geq 0.7$ & $6677(27 \%)$ & $2733(27 \%)$ & $2351(25 \%)$ & \\
\hline No spirometry & $6639(26 \%)$ & $2453(24 \%)$ & $2297(24 \%)$ & \\
\hline \multicolumn{5}{|l|}{ Medications (use in 2015) } \\
\hline LABAs & $8628(34 \%)$ & 3452 (34\%) & 3112 (33\%) & $<0.01$ \\
\hline LAMA & $7332(29 \%)$ & $2797(27 \%)$ & $2361(25 \%)$ & $<0.01$ \\
\hline ICS & $8804(35 \%)$ & $3512(34 \%)$ & $3195(33 \%)$ & 0.02 \\
\hline LAMA and ICS & $3850(15 \%)$ & $1448(14 \%)$ & $1131(12 \%)$ & $<0.01$ \\
\hline LABA and ICS & $8367(33 \%)$ & 3335 (33\%) & 3018 (32\%) & $<0.01$ \\
\hline Long-term systemic corticosteroids & $311(1 \%)$ & $107(1 \%)$ & $82(1 \%)$ & $<0.01$ \\
\hline Oxygen use & $4310(17 \%)$ & $1154(11 \%)$ & $656(7 \%)$ & $<0.01$ \\
\hline \multicolumn{5}{|c|}{ Comorbidities (all available data, 2011-2015) } \\
\hline Charlson Comorbidity Index & $3.5(2.41)$ & $3.0(2.15)$ & $2.6(1.99)$ & $<0.01$ \\
\hline Quartile $1(0-1)$ & $5538(22 \%)$ & $2847(28 \%)$ & $3289(34 \%)$ & $<0.01$ \\
\hline Quartile 2 (2) & $5144(20 \%)$ & $2491(24 \%)$ & $2344(25 \%)$ & \\
\hline Quartile 3 (3-4) & $7334(29 \%)$ & $2811(28 \%)$ & $2451(26 \%)$ & \\
\hline Quartile 4 (>4) & $7099(28 \%)$ & $2072(20 \%)$ & $1474(15 \%)$ & \\
\hline
\end{tabular}

Continued 
Table 1 Continued

\begin{tabular}{|c|c|c|c|c|}
\hline & Inactive $(n=25117)$ & $\begin{array}{l}\text { Insufficiently active } \\
\text { ( } n=10221)\end{array}$ & Active $(\mathrm{n}=9558)$ & $P$ value \\
\hline Myocardial infarction & $3028(12 \%)$ & 947 (9\%) & $836(9 \%)$ & $<0.01$ \\
\hline Congestive heart failure & $4480(18 \%)$ & $1168(11 \%)$ & $820(9 \%)$ & $<0.01$ \\
\hline Peripheral vascular disease & $13958(56 \%)$ & $5034(49 \%)$ & $4233(44 \%)$ & $<0.01$ \\
\hline Cerebrovascular disease & $2548(10 \%)$ & $755(7 \%)$ & 557 (6\%) & $<0.01$ \\
\hline Dementia & $361(1 \%)$ & $72(1 \%)$ & $27(0 \%)$ & $<0.01$ \\
\hline Connective tissue disease-rheumatic disease & $1319(5 \%)$ & $424(4 \%)$ & $336(4 \%)$ & $<0.01$ \\
\hline Peptic ulcer disease & $356(1 \%)$ & $95(1 \%)$ & $76(1 \%)$ & $<0.01$ \\
\hline Mild liver disease & $1551(6 \%)$ & $514(5 \%)$ & $506(5 \%)$ & $<0.01$ \\
\hline Diabetes without complications & $2967(12 \%)$ & $1289(13 \%)$ & $1013(11 \%)$ & $<0.01$ \\
\hline Diabetes with complications & $5424(22 \%)$ & $1636(16 \%)$ & $1121(12 \%)$ & $<0.01$ \\
\hline Paraplegia and hemiplegia & $308(1 \%)$ & $63(1 \%)$ & $47(0 \%)$ & $<0.01$ \\
\hline Renal disease & $7463(30 \%)$ & $2459(24 \%)$ & $1863(19 \%)$ & $<0.01$ \\
\hline Cancer & $1879(7 \%)$ & $612(6 \%)$ & $596(6 \%)$ & $<0.01$ \\
\hline Moderate or severe liver disease & $142(1 \%)$ & $41(0 \%)$ & $41(0 \%)$ & 0.06 \\
\hline Metastatic carcinoma & $419(2 \%)$ & $140(1 \%)$ & $93(1 \%)$ & $<0.01$ \\
\hline \multicolumn{5}{|l|}{ Other non-Charlson morbidities } \\
\hline Depression & $7197(29 \%)$ & $2365(23 \%)$ & $1763(18 \%)$ & $<0.01$ \\
\hline Anxiety & $5441(22 \%)$ & $1805(18 \%)$ & $1489(16 \%)$ & $<0.01$ \\
\hline Chronic pain & $5502(22 \%)$ & $1531(15 \%)$ & $1265(13 \%)$ & $<0.01$ \\
\hline
\end{tabular}

$\mathrm{FEV}_{1}$, forced expiratory volume in one second; FVC, forced vital capacity; GOLD, Global initiative for chronic obstructive lung disease; ICS, inhaled corticosteroid; LABA, long-acting beta-agonist; LAMA, long-acting anticholinergic.

Table 2 Baseline healthcare use by self-reported moderate to vigorous physical activity (exercise vital sign)

\begin{tabular}{|c|c|c|c|c|}
\hline & Inactive $(n=25117)$ & $\begin{array}{l}\text { Insufficiently active } \\
(n=10221)\end{array}$ & Active $(n=9558)$ & $P$ value \\
\hline \multicolumn{5}{|c|}{ Baseline healthcare use (Oct 2014-Sept 2015) } \\
\hline \multicolumn{5}{|l|}{ All cause } \\
\hline \multirow[t]{2}{*}{ Hospitalisations } & $5869(23 \%)$ & $1461(14 \%)$ & $1036(11 \%)$ & $<0.01$ \\
\hline & $0.4(0.93)$ & $0.2(0.64)$ & $0.2(0.58)$ & $<0.01$ \\
\hline \multirow[t]{2}{*}{ Observational stays } & $1830(7 \%)$ & $485(5 \%)$ & $338(4 \%)$ & $<0.01$ \\
\hline & $0.1(0.34)$ & $0.1(0.25)$ & $0.0(0.26)$ & $<0.01$ \\
\hline \multirow[t]{2}{*}{ Emergency department visits } & $9258(37 \%)$ & $2829(28 \%)$ & $2369(25 \%)$ & $<0.01$ \\
\hline & $0.8(1.74)$ & $0.5(1.26)$ & $0.4(1.33)$ & $<0.01$ \\
\hline Primary care visits & $4.9(4.75)$ & $4.2(3.92)$ & $4.1(4.27)$ & $<0.01$ \\
\hline Specialty care visits & $9.7(12.48)$ & $8.2(10.82)$ & $8.4(12.51)$ & $<0.01$ \\
\hline \multicolumn{5}{|l|}{ COPD-related acute care encounters } \\
\hline \multirow[t]{2}{*}{ Hospitalisations } & $1045(4 \%)$ & $258(3 \%)$ & $141(1 \%)$ & $<0.01$ \\
\hline & $0.2(0.47)$ & $0.1(0.33)$ & $0.1(0.26)$ & $<0.01$ \\
\hline \multirow[t]{2}{*}{ Observational stays } & $244(1 \%)$ & $73(1 \%)$ & $35(0 \%)$ & $<0.01$ \\
\hline & $0.0(0.18)$ & $0.0(0.16)$ & $0.0(0.12)$ & $<0.01$ \\
\hline \multirow[t]{2}{*}{ Emergency department visits } & $1208(5 \%)$ & $359(4 \%)$ & $226(2 \%)$ & $<0.01$ \\
\hline & $0.2(0.56)$ & $0.1(0.44)$ & $0.1(0.37)$ & $<0.01$ \\
\hline \multirow[t]{2}{*}{ Outpatient treated exacerbations } & $9550(38 \%)$ & $3340(33 \%)$ & $2992(31 \%)$ & $<0.01$ \\
\hline & $0.7(1.16)$ & $0.5(1.00)$ & $0.5(1.00)$ & $<0.01$ \\
\hline
\end{tabular}

COPD, chronic obstructive pulmonary disease. 
Table 3 Association between self-reported moderate to vigorous physical activity and rate of outpatient treated COPD exacerbations over 2 years of follow-up

\begin{tabular}{|c|c|c|c|c|}
\hline & $\begin{array}{l}\text { Outpatient treated } \\
\text { COPD exacerbations } \\
\text { n (\%), mean (SD) }\end{array}$ & Crude IRR & Unadjusted IRR (95\% Cl) & Adjusted IRR* $(95 \%$ Cl) \\
\hline \multicolumn{5}{|l|}{ All patients ( $\mathrm{N}=44896)$} \\
\hline Inactive (25 117) & 12483 (50\%), 1.24 (2.04) & Ref & Ref & Ref \\
\hline Insufficiently active (10 221) & $4882(48 \%), 1.14$ (1.90) & 0.92 & 0.93 (0.91 to 0.95$)$ & 0.98 (0.96 to 1.01$)$ \\
\hline Active (9558) & 4440 (46\%), 1.07 (1.84) & 0.86 & 0.86 (0.84 to 0.88$)$ & 0.97 (0.95 to 0.98$)$ \\
\hline \multicolumn{5}{|l|}{$\mathrm{FEV}_{1} / \mathrm{FVC}<0.7(\mathrm{n}=21746)$} \\
\hline \multicolumn{5}{|l|}{ GOLD I (n=5733) } \\
\hline Inactive (2795) & $1330(48 \%), 1.09(1.87)$ & Ref & Ref & Ref \\
\hline Insufficiently active (1322) & 581 (44\%), 0.95 (1.64) & 0.87 & 0.89 (0.84 to 0.95$)$ & $1.03(0.97$ to 1.11$)$ \\
\hline Active (1616) & 722 (45\%), 0.95 (1.62) & 0.87 & 0.88 (0.83 to 0.93$)$ & $1.0(0.94$ to 1.07$)$ \\
\hline \multicolumn{5}{|l|}{ GOLD II (n=11 613) } \\
\hline Inactive (6401) & $3570(56 \%), 1.47(2.20)$ & Ref & Ref & Ref \\
\hline Insufficiently active (2695) & 1461 (54\%), 1.37 (2.16) & 0.93 & 0.94 (0.91 to 0.98$)$ & 0.99 (0.95 to 1.04$)$ \\
\hline Active (2517) & $1355(54 \%), 1.29(2.01)$ & 0.88 & 0.88 (0.85 to 0.92$)$ & 1.02 (0.98 to 1.06$)$ \\
\hline \multicolumn{5}{|l|}{ GOLD III/IV $(n=4400)$} \\
\hline Inactive (2605) & 1737 (67\%), 2.22 (2.85) & Ref & Ref & Ref \\
\hline Insufficiently active (1018) & 648 (64\%), 1.97 (2.66) & 0.89 & 0.90 (0.85 to 0.94$)$ & 0.95 (0.9 to 1.0$)$ \\
\hline Active (777) & 517 (67\%), 2.04 (2.69) & 0.92 & 0.93 (0.88 to 0.98$)$ & 0.95 (0.9 to 1.0$)$ \\
\hline \multicolumn{5}{|l|}{$\mathrm{FEV}_{1} / \mathrm{FVC} \geq 0.7 \quad(n=11761)$} \\
\hline Inactive (6677) & 2843 (43\%), 0.91 (1.61) & Ref & Ref & Ref \\
\hline Insufficiently active (2733) & 1097 (40\%), 0.84 (1.5) & 0.92 & 0.93 (0.89 to 0.98$)$ & $0.9(0.85$ to 0.95$)$ \\
\hline Active (2351) & 876 (37\%), 0.72 (1.39) & 0.79 & 0.79 (0.75 to 0.83$)$ & 1.05 (0.98 to 1.12$)$ \\
\hline \multicolumn{5}{|l|}{ No spirometry ( $n=11389$ ) } \\
\hline Inactive (6639) & 3003 (45\%), 1.03 (1.78) & Ref & Ref & Ref \\
\hline Insufficiently active (2453) & 1095 (45\%), 0.97 (1.57) & 0.94 & 0.95 (0.90 to 0.99$)$ & 0.97 (0.92 to 1.03$)$ \\
\hline Active (2297) & 970 (42\%), 0.93 (1.69) & 0.90 & 0.91 (0.86 to 0.95$)$ & 1.03 (0.98 to 1.08$)$ \\
\hline
\end{tabular}

*Adjusted models accounted for age, gender, marital status, race/ethnicity, smoking status, use of inhaled steroids and oxygen, comorbidity, depression, anxiety, chronic pain, all-cause acute care use (hospitalisation, observation stay and emergency department visits), and baseline outpatient treated COPD exacerbations in the previous 12 months. Sample sizes for unadjusted and adjusted models may vary by $\sim 100$ to 345 fewer than the listed $n$ for each subgroup primarily due to missing body mass index $(n=344)$.

COPD, chronic obstructive pulmonary disease; $\mathrm{FEV}_{1}$, forced expiratory volume in one second; FVC, forced vital capacity; GOLD, Global initiative for chronic obstructive lung disease; IRR, incidence rate ratio; Ref, reference.

spirometry data. The negative binomial models provided similar point estimates but with wider CIs.

\section{DISCUSSION}

We found that the association between baseline moderate to vigorous PA captured as part of routine care and the rate of mild to moderate outpatient treated AECOPD over 2 years of follow-up was generally weak or non-significant, which is in contrast to the strong relationship observed between PA and hospitalisations for severe exacerbations, despite differences in how PA was measured and classified across these prior studies. ${ }^{1-7}$ To the best of our knowledge, this is the first 'real-world' large-scale study to examine the association between self-reported PA, captured during routine care, with AECOPD in an entire clinical population of patients diagnosed with COPD from an integrated healthcare system.
The weak to null findings in this study could partly be attributed to the difficulty of capturing AECOPD in the EMR and incomplete ascertainment of these events in contrast to near complete capture of severe AECOPD that result in hospitalisations, in combination with the imprecision and errors associated with self-reported PA. ${ }^{13}$ Given the need for any behavioural assessment to be streamlined for use in routine care across broad populations and for different clinical and population surveillance purposes, ${ }^{14}$ the self-reported measure of PA used in this study only provides an overall assessment of 'regular' $\mathrm{PA}$ in the previous year and did not distinguish between light, moderate and vigorous activities. ${ }^{9}$ A recent study of 177 patients with stable COPD that measured PA with an accelerometer over an 8-day period found that for every increase of 1000 daily steps at low average intensity, the risk of COPD hospitalisation was reduced by $20 \%$ over a 
2-year period; high-intensity PA was not associated with any risk reduction. ${ }^{5}$ In our previous paper, using the same self-reported moderate to vigorous PA measure as the current study, we also found a significant risk reduction $(34 \%)$ in 30-day readmissions for 4596 patients with COPD who reported engaging in any amount of PA. ${ }^{6}$ It is possible that, although the PA questions asked about moderate to vigorous exercise, patients may have actually reported on what would be perceived as lower intensity activities in normal adults without airflow obstruction and that the challenge we faced in this study had more to do with difficulties capturing the AECOPD events using data that were intended for clinical care, not research purposes. Interestingly, a recent meta-analysis of 39 studies reported that higher levels of total PA, at any intensity, was associated with lower risk of mortality. ${ }^{15}$

Another limitation of the study was that our models did not include other intervening events and changes in PA patterns over the 2 years of follow-up. With broader use of biometric sensors, future studies could improve on these methods by using objective PA data combined with electronic logs of symptoms, sensors to detect changes in breathing patterns and treatments to explore the real-time, dynamic relationships between different PA intensities and AECOPD across a broad, representative population of patients with COPD. ${ }^{16} 17$

In conclusion, although our findings show little to no association between PA and the rate of AECOPD based on data obtained as part of routine clinical care, the positive health effects of $\mathrm{PA}$ is indisputable based on the existing high-quality evidence base regarding the survival benefits of PA in COPD ${ }^{1-4} 71819$ and healthy adults and older adults. ${ }^{152021}$

\section{Contributors Contributions from all authors meet the ICMJE authorship criteria.}

Funding This study used the infrastructure developed by the Patient Outcomes Research to Advance Learning Network, a consortium of three integrated healthcare delivery systems (Kaiser Permanente, HealthPartners and Denver Health) and their affiliated research centres. Research reported in this article was funded through a Patient-Centered Outcomes Research Institute (PCORI) award (CDRN-1306-04681, phase II). The statements and opinions in this publication are solely the responsibility of the authors and do not necessarily represent the views of the PCORI, its board of governors or methodology committee.

\section{Competing interests None declared.}

Patient and public involvement Patients and/or the public were not involved in the design, or conduct, or reporting, or dissemination plans of this research.

Patient consent for publication Not required.

Ethics approval Kaiser Permanente Southern California and Kaiser Permanente Pacific Northwest institutional review boards approved this study.

Provenance and peer review Not commissioned; internally peer reviewed.

Data availability statement Data are available upon reasonable request. Due to the significant time and costs associated with the removal of all identifiers to protect the identities of participants, the requester will be asked to incur these costs.

Open access This is an open access article distributed in accordance with the Creative Commons Attribution Non Commercial (CC BY-NC 4.0) license, which permits others to distribute, remix, adapt, build upon this work non-commercially, and license their derivative works on different terms, provided the original work is properly cited, appropriate credit is given, any changes made indicated, and the use is non-commercial. See: http://creativecommons.org/licenses/by-nc/4.0/.

\section{REFERENCES}

1 Garcia-Aymerich J, Lange P, Benet M, et al. Regular physical activity reduces hospital admission and mortality in chronic obstructive pulmonary disease: a population based cohort study. Thorax 2006;61:772-8.

2 Garcia-Rio F, Rojo B, Casitas R, et al. Prognostic value of the objective measurement of daily physical activity in patients with COPD. Chest 2012;142:338-46.

3 Vaes AW, Garcia-Aymerich J, Marott JL, et al. Changes in physical activity and all-cause mortality in COPD. Eur Respir J 2014.

4 Waschki B, Kirsten A, Holz O, et al. Physical activity is the strongest predictor of all-cause mortality in patients with COPD: a prospective cohort study. Chest 2011;140:331-42.

5 Donaire-Gonzalez D, Gimeno-Santos E, Balcells E, et al. Benefits of physical activity on COPD hospitalisation depend on intensity. Eur Respir J 2015;46:1281-9.

6 Nguyen HQ, Chu L, Amy Liu I-L, Liu IL, et al. Associations between physical activity and 30-day readmission risk in chronic obstructive pulmonary disease. Ann Am Thorac Soc 2014;11:695-705.

7 Moy ML, Gould MK, Liu I-LA, et al. Physical activity assessed in routine care predicts mortality after a COPD hospitalisation. ERJ Open Res 2016;2. doi:10.1183/23120541.00062-2015. [Epub ahead of print: 1703 2016].

8 Deyo RA, Cherkin DC, Ciol MA. Adapting a clinical comorbidity index for use with ICD-9-CM administrative databases. J Clin Epidemiol 1992;45:613-9.

9 Coleman KJ, Ngor E, Reynolds K, et al. Initial validation of an exercise "vital sign" in electronic medical records. Med Sci Sports Exerc 2012;44:2071-6.

10 Liu IA, Moy ML, Estrada E, et al. An 'Exercise Vital Sign' is a Valid Proxy Measure of Physical Activity in COPD in Routine Clinical Care. Translational J of the American College of Sports Medicine 2017;2:148-52.

11 Anthonisen NR, Manfreda J, Warren CP, et al. Antibiotic therapy in exacerbations of chronic obstructive pulmonary disease. Ann Intern Med 1987;106:196-204.

12 Ko S, Greif S, Lee J, et al. Validating an automated algorithm to identify outpatient treated COPD exacerbations using electronic medical records data paper. San Diego, CA: presented at: American Thoracic Society, 2016.

13 Troiano RP, Berrigan D, Dodd KW, et al. Physical activity in the United States measured by accelerometer. Med Sci Sports Exerc 2008;40:181-8.

14 Committee on the Recommended Social and Behavioral Domains and Measures for Electronic Health Records; Board on Population Health and Public Health Practice. Capturing Social and Behavioral Domains in Electronic Health Records: Phase 1. Washington (DC: National Academies Press (US): Institute of Medicine, 2014.

15 Ekelund U, Tarp J, Steene-Johannessen J, et al. Dose-Response associations between accelerometry measured physical activity and sedentary time and all cause mortality: systematic review and harmonised meta-analysis. BMJ 2019;366:14570.

16 Sumino K, Locke ER, Magzamen S, et al. Use of a remote inhaler monitoring device to measure change in inhaler use with chronic obstructive pulmonary disease exacerbations. J Aerosol Med Pulm Drug Deliv 2018;31:191-8.

17 Bowler R, Allinder M, Jacobson S, et al. Real-World use of rescue inhaler sensors, electronic symptom questionnaires and physical activity monitors in COPD. BMJ Open Respir Res 2019;6:e000350.

18 Waschki B, Kirsten AM, Holz O, et al. Disease progression and changes in physical activity in patients with chronic obstructive pulmonary disease. Am J Respir Crit Care Med 2015;192:295-306.

19 Moy ML, Teylan M, Weston NA, et al. Daily step count predicts acute exacerbations in a US cohort with COPD. PLoS One 2013;8:e60400.

20 Biswas A, Oh PI, Faulkner GE, et al. Sedentary time and its association with risk for disease incidence, mortality, and hospitalization in adults: a systematic review and meta-analysis. Ann Intern Med 2015;162:123-32.

21 Lee I-M, Shiroma EJ, Kamada M, et al. Association of step volume and intensity with all-cause mortality in older women. JAMA Intern Med 2019. doi:10.1001/jamainternmed.2019.0899. [Epub ahead of print: 29 May 2019]. 